-Original-

\title{
Distribution of Bone Marrow-Derived Cells in the Fracture Callus during Plate Fixation in a Green Fluorescent Protein-Chimeric Mouse Model
}

\author{
Masaki UENO $^{1)}$, Kentaro UCHIDA $^{1)}$, Masashi TAKASO ${ }^{1)}$, Hiroaki MINEHARA ${ }^{1)}$, \\ Kaori SUTO ${ }^{1)}$, Naonobu TAKAHIRA ${ }^{1)}$, Roland STECK ${ }^{2)}$, \\ Michael A. SCHUETZ ${ }^{2,3)}$, and Moritoshi ITOMAN ${ }^{4)}$
}

\begin{abstract}
${ }^{1)}$ Kitasato University School of Medicine, Department of Orthopaedic Surgery, 1-15-1 Kitasato, Sagamihara, Kanagawa 228-8555, Japan, ${ }^{2}$ Institute of Health and Biomedical Innovation, Queensland University of Technology, 60 Musk Avenue, Kelvin Grove Urban Village, Kelvin Grove, Queensland 4059, ${ }^{3)}$ Trauma Services, The Princess Alexandra Hospital, 199 Ipswich Road Woolloongabba, Brisbane, Queensland 4102, Australia, and ${ }^{4)}$ Department of Orthopaedic Surgery, Kyushu Rosai Hospital, 1-3-1 Kuzuharatakamastu, Kokuraminami-ku, Kitakyushu, Fukuoka 800-0296, Japan
\end{abstract}

\begin{abstract}
To clarify the distribution of bone-marrow-derived cells in fractures treated by plate fixation, fracture models were created using the green fluorescent protein (GFP) chimeric mouse. We observed 2 types of fracture healing processes with different types of callus formation and cellular events by using Mouse $\mathrm{Fix}^{\mathrm{TM}}$, a device allowing plate fixation on the mouse femur, and differences in the distribution of bone-marrow-derived cells between the 2 types. The GFP chimeric mice were created by bone marrow transplantation. Fractures were created on the left femurs of mice and stabilized with either rigid (Group R) or flexible (Group F) plates to prepare undecalcified fresh-frozen sections. In Group F, a large external callus and a large intramedullary callus were formed mostly by endochondral ossification. The cells that made up the intramedullary callus and callus in the fracture gap were GFP positive, but most cells of the external callus were not. In Group R, bone union was achieved mostly without external callus formation, bone apposition occurred directly in the gap, and a small intramedullary callus was formed. As observed in Group F, this group had GFP-positive cells in the callus within the fracture gap and in the intramedullary calluses. The results of this study provided direct evidence of the distribution of bone-marrow-derived cells in the callus of fractures treated by plate fixation under different stability conditions.
\end{abstract}

Key words: bone marrow, callus formation, fracture, green fluorescent protein, plate

\section{Introduction}

Bone marrow cells (BMCs) are closely related to the fracture healing process. Several studies on the relation- ship between bone marrow and fracture have reported that endothelial progenitor cells contributing to enhanced neovascularization at the fracture site are specifically derived from bone marrow [14] and that the osteoblasts

(Received 7 March 2011 / Accepted 12 May 2011)

Address corresponding: M. Ueno, Department of Orthopaedic Surgery, Kitasato University School of Medicine, 1-15-1 Kitasato, Sagamihara, Kanagawa 228-8555, Japan 
making up the calluses are derived from bone marrow [22].

The fracture healing process is influenced by the mechanical environment at the fracture site [1, 4, 19]. When the fracture is highly stable, with only a small gap between bone fragments, the gap is directly filled with the bone matrix. Additionally, if the fracture is anatomically reduced at the micrometric level, "primary fracture healing" occurs without external callus formation [5]. Endochondral bone formation usually occurs external to the periosteum in regions that are mechanically less stable and immediately adjacent to the fracture site, whereas intramembranous ossification occurs internal to the periosteum at the proximal and distal edges of the callus, thereby leading to the formation of a hard callus $[6,7]$. Thus, fracture healing is not homogeneous throughout the callus. Callus formations are seen in 3 areas - the medullary canal, the area between the cortices, and the extramedullary area including the subperiosteal layer and the surrounding soft tissues. However, the origin of the cells forming the calluses in different fracture healing processes remains unclear.

Recently, the AO Development Institute (AO Foundation, Davos, Switzerland) developed Mouse Fix ${ }^{\mathrm{TM}}$, a device allowing observation of fracture healing by plate fixation on the mouse femur $[10,15]$. We already reported that the use of different types of plates with the Mouse Fix ${ }^{\mathrm{TM}}$ system leads to 2 different types of fracture healing, with differences in the type of callus formation and cellular events [10, 24].

To clarify the distribution of bone-marrow-derived cells in the fracture callus of the plate fixation, fracture models were created using green fluorescent protein (GFP) chimeric mice. We observed 2 types of fracture healing processes by using Mouse Fix ${ }^{\mathrm{TM}}$ and noted differences in the distribution of bone-marrow-derived cells between the 2 types of fracture healing processes.

\section{Materials and Methods}

All surgeries and handling procedures were in accordance with the guidelines of the Animal Ethics Committee of Kitasato University.

\section{Establishment of GFP-chimeric mouse models}

Twelve eight-week-old male C57BL/6 and six eightweek-old male GFP transgenic C57BL/6 mice were used for this experiment. Bone marrow transplantation was performed with C57BL/6 GFP mice as donors and C57BL/6 mice as recipients. Donor BMCs were obtained from the femurs and tibias of the GFP-expressing mice. Prior to transplantation, the recipient mice were irradiated with fractionated doses of x-rays (10 Gy). One day after irradiation, the C57BL/6 mice were transplanted with the entire amount of collected BMCs $\left(3 \times 10^{7} / 10\right.$ $\mu 1)$ by intra-bone marrow injections administered in the right knee $[23,26]$. A 5-mm incision was made in the right thigh, the knee was flexed to 90 degrees, and the donor BMCs were injected into the marrow cavity of the tibia using a microsyringe equipped with a 27-gauge needle. After seven weeks, peripheral cells were collected from the recipient mice and then analyzed using a fluorescence-activated cell sorter (FACS) Calibur flow cytometer (BD Biosciences, San Jose, CA, USA) to identify the donor-derived cells.

\section{Creation of the fracture}

After eight weeks, fractures were induced and then stabilized with Mouse Fix ${ }^{\mathrm{TM}}$ implants in either a rigid (Fig. 1A) or flexible (Fig. 1B) configuration. We have already confirmed that we can observe two distinct cellular events at the fracture healing site using two Mouse Fix $^{\mathrm{TM}}$ plates with different levels of flexibility [24]. By the same technique, a mixture of 1 part midazolam, 3 parts Domitor ${ }^{\mathrm{TM}}$, and 1 part Vetorphale ${ }^{\mathrm{TM}}$ was then intramuscularly injected into the upper limbs at an optimal dose of $0.05 \mathrm{ml} / 100 \mathrm{~g}$. The operation was performed only on the left femur. After the plate and screw were implanted, the bone was cut gently using a wire saw (diameter, $0.22 \mathrm{~mm}$ ) to create a gap. The success of the surgical procedure was confirmed radiographically. After the surgery, the mice were allowed to use their fractured legs without restriction.

\section{Preparation of undecalcified fresh-frozen sections of femurs}

Three mice each from both groups were sacrificed by administration of an excess of $\mathrm{CO}_{2}$ gas at 7 and 14 days after fracture induction. After blood was removed by 
A
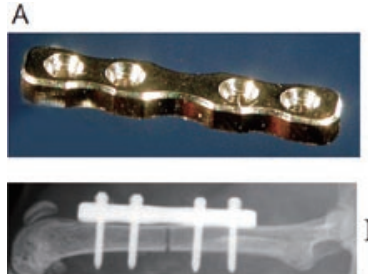

Day 7

B
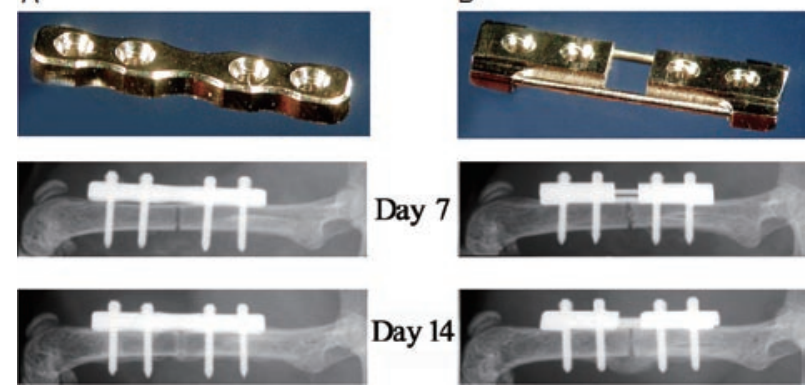

Fig. 1. (A) Rigid plate, (B) flexible plate. There are 4 holes for screw thread cutting. The flexible plate is comprised of two segments bridged by wires that are $0.25 \mathrm{~mm}$ in diameter. Each plate is fixed with locking screws. Representative soft X-ray images of Group R and Group F at two time points after fracture are shown.

cardiopuncture to avoid contamination of the fracture site, the left femurs were excised gently with the surrounding muscle. The implanted plate and screws were removed carefully, and the collected femurs were then immersed in a 5\% carboxymethyl cellulose (CMC) gel for $10 \mathrm{~min}$, transferred to hexane, and completely frozen using solid carbon dioxide. Next, the frozen blocks were fastened to a CM 3050S IV cryomicrotome (Leica Instruments, Heidelberger, Germany) in a cryochamber at $-25^{\circ} \mathrm{C}$ and then trimmed using a disposable tungsten carbide blade. The trimmed surface was covered with a Cryofilm (Finetec, Tokyo, Japan) while using a brush to remove air bubbles behind the film [13]. The femur samples were then cut into $6-\mu \mathrm{m}$-thick sections with the tungsten carbide blade and dried at $-25^{\circ} \mathrm{C}$. After drying, the distribution of bone marrow-derived cells at the fracture site was examined by fluorescence microscopy. The serial sections were also stained with alkaline phosphatase (ALP) and Von Kossa stain (Kureha Special Laboratory Co., Ltd., Tokyo, Japan).

\section{Results}

To identify the donor-derived cells, peripheral cells collected from GFP-chimeric mice were analyzed using a FACS calibur seven weeks after bone marrow transplantation in C57BL/6 mice (Fig. 2). In all 12 transplanted mice, $98 \%$ of the BMCs were GFP positive, while nearly all of the blood cells appeared to have been

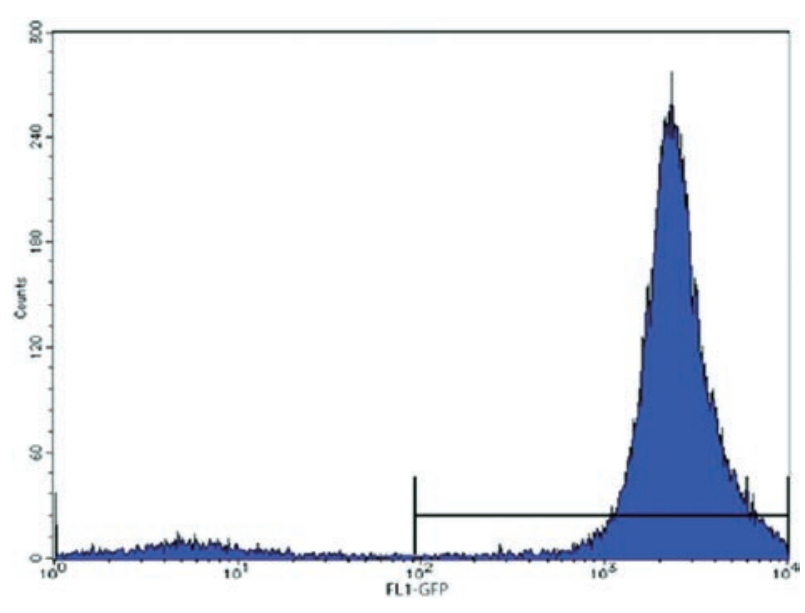

Fig. 2. BMCs from GFP-chimeric mice were analyzed with a FACS Calibur flow cytometer seven weeks after bone marrow transplantation in C57BL/6 mice. In all examined mice, $98 \%$ of bone marrow mononuclear cells were GFP positive, and it appeared that nearly all of the blood cells had been reconstituted.

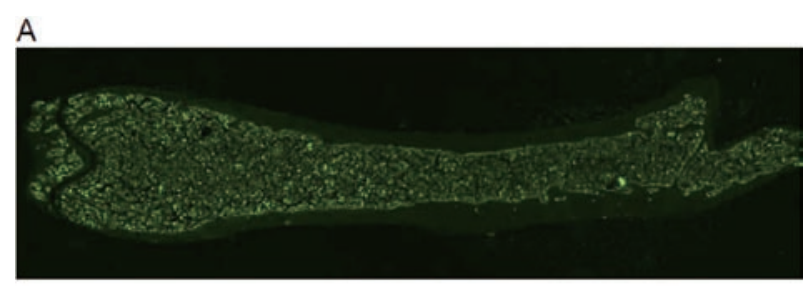

B

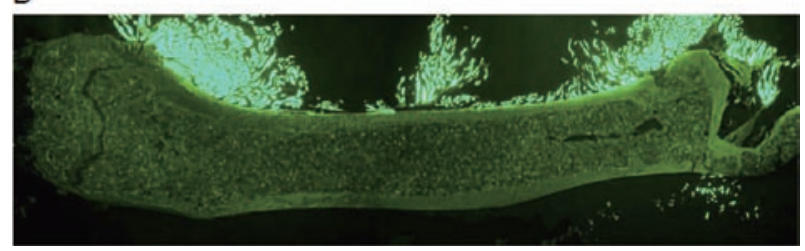

Fig. 3. (A) Thin-sectioned femurs of GFP-chimeric and (B) GFPtransgenic mice. In the femurs from GFP-chimeric mice, the BMCs were confirmed to be GFP positive, whereas the bone, muscle, and subcutaneous tissue cells were GFP negative. All cells of the GFP-transgenic mice were GFP positive.

reconstituted. BMCs collected from nonfractured femurs were confirmed to be GFP positive, whereas the cells of the bone, muscle and subcutaneous tissues were GFP negative, as determined by fluorescence microscopy (Fig. 3A). All cells of the GFP-transgenic mice were GFP positive (Fig. 3B).

Eight weeks after the transplantation of BMCs from 

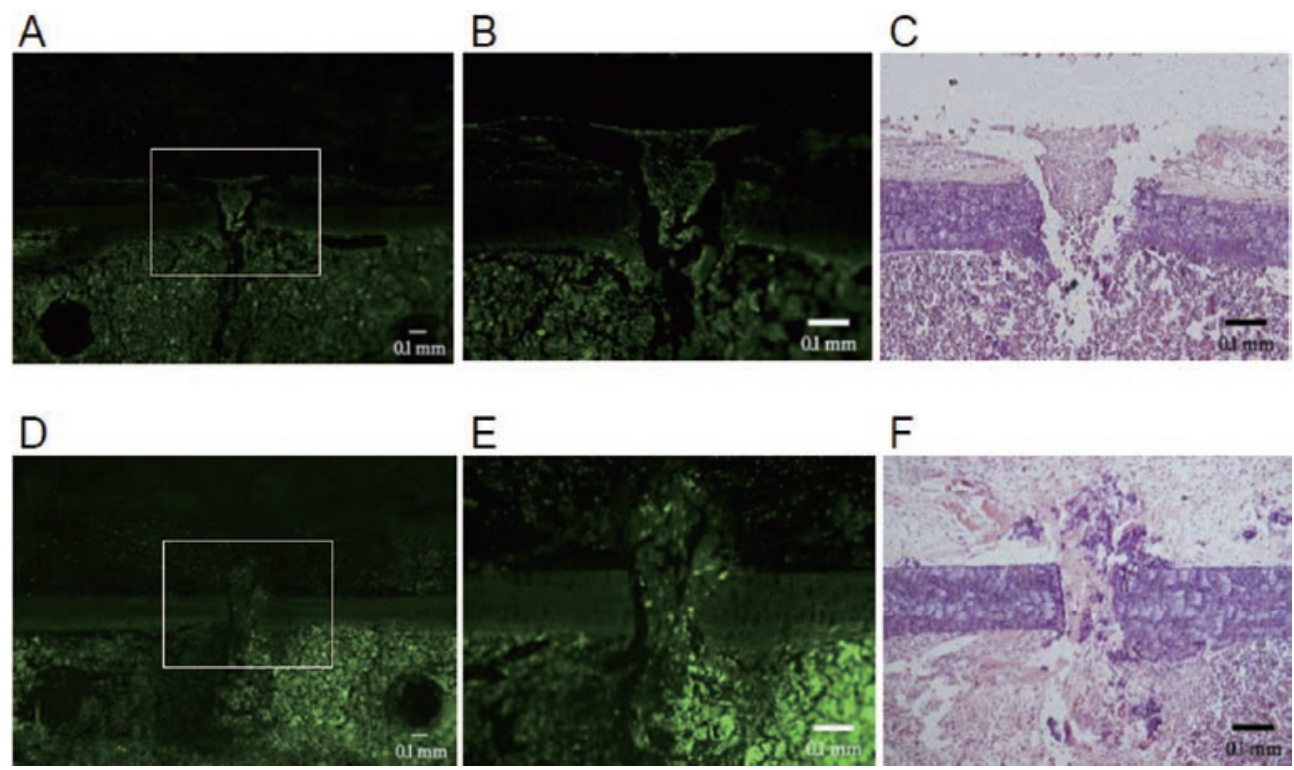

Fig. 4. Tissue samples of the undecalcified fresh-frozen sections prepared from Group R and F mice on day 7. (A) Fluorescence micrograph, (B) magnified image of A, and (C) hematoxylin and eosin (HE)-stained section from Group R. (D) Fluorescence micrograph, (E) magnified image of D, and (F) HE-stained section from Group F.

C57BL/6 GFP mice, fractures were induced in the two groups of recipient $\mathrm{C} 57 \mathrm{BL} / 6$ mice. The distribution of $\mathrm{BMCs}$ during the healing process was monitored at several time points in undecalcified fresh-frozen sections of femurs from GFP-chimeric mice by fluorescence microscopy and HE staining (Figs. 4 and 5). In Group R mice, the HE-stained sections of femurs obtained from day seven mice clearly showed subperiosteal cell proliferation and intramembranous ossification peripheral to the fracture site, while newly formed woven bone was observed within the fracture gap (Fig. 4C). In the corresponding fluorescence images, GFP-expressing cells were localized in the woven bone of the gap (Fig. 4A and $4 \mathrm{~B}$ ). Inflammatory cells above the proliferated periosteum were also GFP positive. On day 14, the HEstained sections exhibited remodeling of woven bone in the fracture gap, while a small intramedullary callus had formed, and a mature bone layer had formed under the periosteum by continuous intramembranous ossification (Fig. 5C). In the fluorescence images, GFP-expressing cells were observed in the callus of the gap, and a single GFP-positive layer was observed in the cortex (Fig. 5A and $5 \mathrm{~B}$ ). Moreover, the woven bone in the gap consisted of ALP- and Von Kossa-positive cells (Fig. 5D and 5E).

In the Group F mice, HE-stained sections prepared on day seven following fracture showed fibroblastic cell proliferation and formation of cartilage, with an increase in the size of the external callus (Fig. 4F). The fracture gap was also filled with fibrous tissue, and newly formed woven bone had developed in the medullary callus. In the corresponding fluorescence micrograph, GFP-positive cells were observed in the proximity of the fracture ends, including the region of the external callus immediately above the gap (Fig. 4D and 5E). On day 14, the HE-stained sections showed endochondral ossification originating from the surrounding trabecular bone and extending to the center of the external callus (Fig. 5H). In the intramedullary callus, remodeling of the woven bone was noted, while the cells of the callus within and around the fracture gap were GFP positive. In addition, a few GFP-positive cells were located at the sites of newly formed trabecular bone in the external and intramedullary calluses (Fig. 5F and 5G). Most of the external callus that showed endochondral ossification was stained by ALP. The intramedullary callus and woven bone in the gap consisted of both GFP- and ALPpositive cells. Von Kossa-stained sections showed 


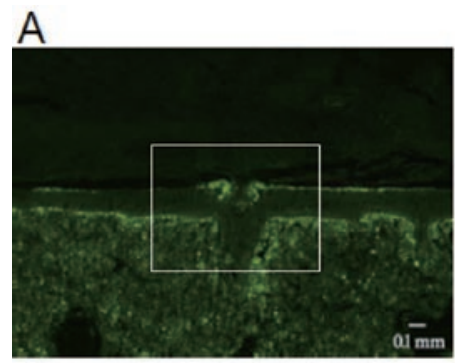

D

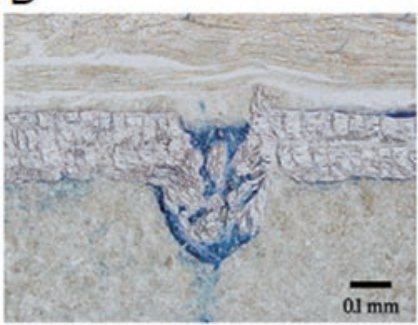

C

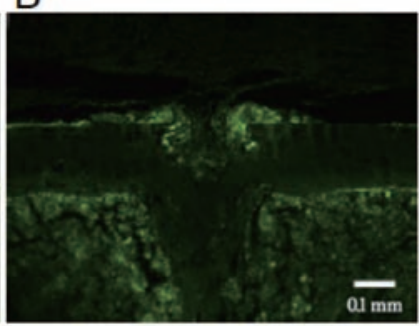

E

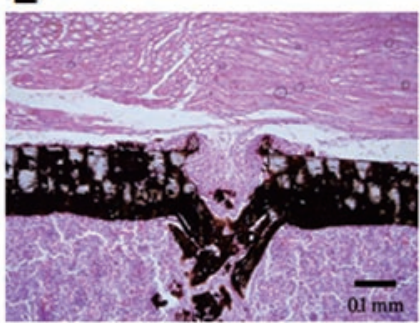

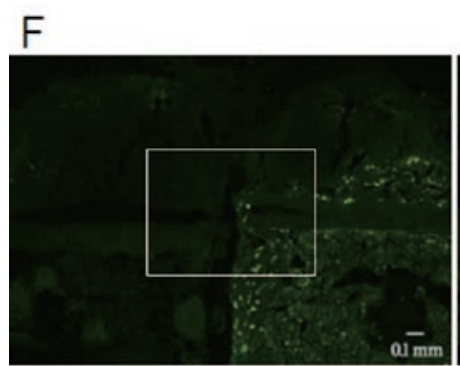

\section{G}

$\mathrm{H}$
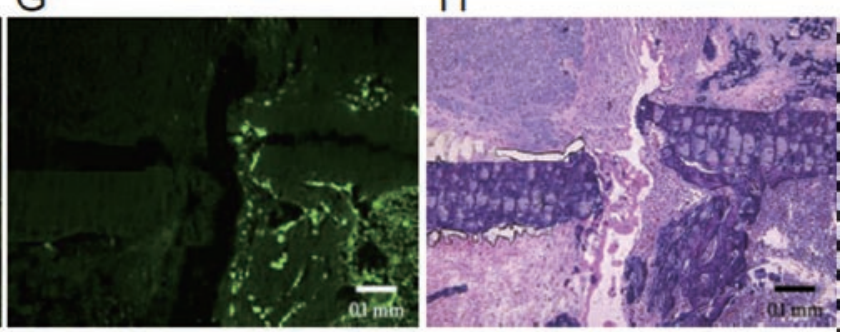

I
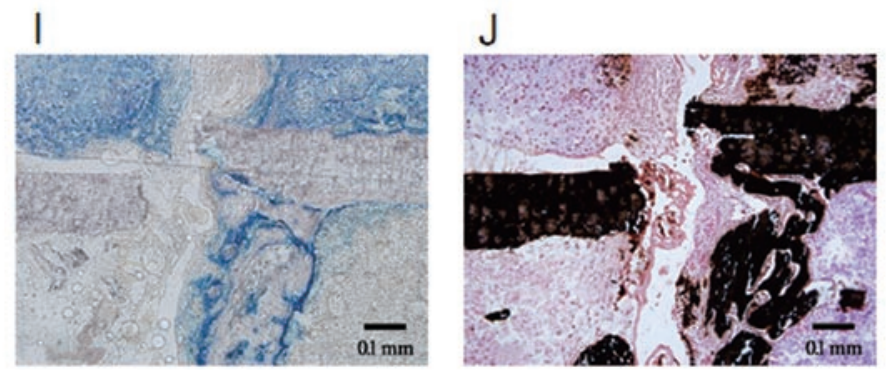

Fig. 5. Tissue samples of the undecalcified fresh-frozen sections prepared from Group $\mathrm{R}$ and $\mathrm{F}$ mice on day 14. (A) Fluorescence micrograph, (B) magnified image of A, (C) hematoxylin and eosin (HE)stained section, (D) ALP-stained section, and (E) Von Kossa-stained section from Group R. (F) Fluorescence micrograph, (G) magnified image of F, (H) HE-stained section, (I) ALP-stained section, and $(\mathrm{J})$ Von Kossa-stained section from Group F.

newly formed trabecular bone in the external and intramedullary calluses (Fig. 5J).

\section{Discussion}

In the Group F mice, in which the formation of large external and intramedullary calluses by chondrogenesis and endochondral ossification was observed, cells comprising the intramedullary and fracture-gap calluses were GFP positive, but almost no GFP-positive cells were observed in the large external callus during its formation. In contrast, bone union in the Group R mice, which was achieved almost entirely without external callus formation and with only a small intramedullary callus, and 
cells in the fracture gap and those of the intramedullary calluses were GFP positive, as observed in Group F. Our results indicate that the cells constituting the intramedullary and fracture-gap calluses are derived from bone marrow, regardless of the fracture stability, and that bone-marrow derived cells are almost absent in external calluses.

By using the GFP chimeric mouse model with intramedullary rods for fixation, Taguchi et al. showed that BMCs such as mesenchymal stem cells or osteoblast progenitor cells migrated outside to form the external callus [22]. However, the GFP is affected by the procedures adopted for tissue fixation or processing [11]. Paraffin embedding results in loss of the GFP signal and a high autofluorescent background. Direct observation of the undecalcified fresh-frozen sections in this study revealed that most cells were GFP negative in the external callus during the formation of the callus in Group F. We recently showed that endogenous FGF-2 expression in periosteal cells with flexible fixation is higher compared with cells with rigid fixation and that FGF-2 expression is one of the factors controlling the size of external calluses [24]. In that report, the results of FGF-2 and PCNA staining in the early phase after fracture showed that the expressions were concentrated above the periosteum, not near the fracture site. Taken together, these results indicate that most of the external callus may be composed of cells derived from the cambium layer of the periosteum. However, small numbers of GFP-expressing cells were found at the newly formed medullary cavity in the external callus. Therefore, BMCs may be partially involved in the formation of the external callus.

Several studies have reported that larger interfragmentary movement generally led to increased callus formation [19]. Several studies performed using models of rabbit osteotomized femur or rat osteotomized tibia with intramedullary rods for fixation have also reported that rigid fixation induces formation of a smaller callus [16, 25]. Although these differences in the fracture healing process have been verified in clinical practice and experiments on large animals, the exact distribution of bone-marrow-derived cells in the fracture callus with a plate in a stable environment has not been elucidated. Our results showed that the cells of the callus formed in the fracture gap under a stable environment were GFP positive, which indicates that these cells were derived from the bone marrow. This mode of fracture healing leads to the formation of a poor external callus and small intramedullary callus. This indicated that bone-marrowderived cells play a significant role in this mode of fracture healing.

This study is the first to use a GFP chimeric mouse model for the observation of fracture healing with plate fixation. Although it is widely accepted that BMCs are closely related to the fracture healing process, studies on the response of the bone marrow to a fracture have mostly been conducted using in vivo experiments employing the intramedullary fixation method with wires or needles. The marrow cavity is severely affected by the fixation implant, which limits the clinical application of these implants. When using an intramedullary nail, histological changes in the marrow cavity cannot be observed because the nail occupies the bone marrow. However, with Mouse $\mathrm{Fix}^{\mathrm{TM}}$, observation of the marrow cavity is possible. In another study using the Mouse Fix $^{\mathrm{TM}}$ model, we showed detailed chronological changes in histology [24]. In Group F, a large intramedullary callus, a so-called "sealing callus", was formed along with an external callus. The sealing callus can also take the form of endochondral ossification, in which cartilage cells appear and ossification starts from the outside extending to the center. Meanwhile, only a small intramedullary callus was created in Group R. The cells of the intramedullary callus were GFP positive, indicating that they were bone-marrow-derived cells, regardless of stability at the fracture site.

Many investigations are currently being undertaken to investigate exogenous applications targeted at various cells to promote the fracture healing process. FGF-2 is recognized as a potent mitogen for a variety of mesenchymal cells $[8,20]$ and has been reported to have an anabolic effect on bone formation, both with local and systemic administrations $[12,17,18]$. It has been established that BMP-2 induces the differentiation of OPCs into osteocytes $[2,3]$ and plays a highly significant role in the control of the fracture healing process $[9,21]$. Our present study demonstrates that distinct levels of flexibility of the plates lead to the differences in the cellular events occurring during fracture healing and in the distribution of the bone-marrow-derived cells in the fracture 
callus. Our findings provide evidence for advanced basic research to promote the fracture healing process with exogenous manipulation.

A few limitations of the study warrant mention. First, total GFP-positive BMCs were transplanted into C57BL/6J mice. As bone marrow contains several cell types, such as mesenchymal and hematopoietic stem cells, and hematopoietic lineage cells, we cannot deduce which cell type contributed to callus formation in this investigation. Second, we were unable to distinguish the origin of the cells in the external callus formed in the fracture stabilized with flexible fixation.

In conclusion, we have provided direct evidence concerning the distribution of bone marrow-derived cells in the callus of fractures treated by plate fixation under different stability conditions. Cells that constitute the intramedullary and fracture-gap calluses are derived from bone marrow regardless of fracture stability, but bone-marrow-derived cells are absent from large external calluses that are formed under unstable conditions. Our results suggest that reinforcing the migration and differentiation capacities of BMCs may promote fracture healing.

\section{Acknowledgments}

We would like to thank Synthes Japan Inc. for providing Mouse Fix ${ }^{\mathrm{TM}}$. Synthes Japan Inc. had no involvement in this study aside from providing Mouse Fix $^{\mathrm{TM}}$.

\section{References}

1. Chao, E.Y., Aro, H.T., Lewallen, D.G., and Kelly, P.J. 1989. The effect of rigidity on fracture healing in external fixation. Clin. Orthop. Relat. Res. Apr: 24-35.

2. Cheng, H., Jiang, W., Phillips, F.M., Haydon, R.C., Peng, Y., Zhou, L., Luu, H.H., An, N., Breyer, B., Vanichakarn, P., Szatkowski, J.P., Park, J.Y., and He, T.C. 2003. Osteogenic activity of the fourteen types of human bone morphogenetic proteins (BMPs). J. Bone Joint Surg. Am. 85-A: 15441552.

3. Cho, T.J., Gerstenfeld, L.C., and Einhorn, T.A. 2002. Differential temporal expression of members of the transforming growth factor beta superfamily during murine fracture healing. J. Bone Miner. Res. 17: 513-520.

4. Claes, L.E. and Heigele, C.A. 1999. Magnitudes of local stress and strain along bony surfaces predict the course and type of fracture healing. J. Biomech. 32: 255-266.

5. Danis, R. 1949. Théorie et Pratique de l'Ostéosynthèse, fourth ed., Masson, Paris.

6. Dimitriou, R., Tsiridis, E., and Giannoudis, P.V. 2005. Current concepts of molecular aspects of bone healing. Injury 36: 1392-1404.

7. Einhorn, T.A. 1998. The cell and molecular biology of fracture healing. Clin. Orthop. Relat. Res. Oct: S7-21.

8. Gospodarowicz, D., Ferrara, N., Schweigerer, L., and Neufeld, G. 1987. Structural characterization and biological functions of fibroblast growth factor. Endocr. Rev. 8: 95114.

9. Govender, S., Csimma, C., Genant, H.K., Valentin-Opran, A., Amit, Y., Arbel, R., Aro, H., Atar, D., Bishay, M., Börner, M.G., Chiron, P., Choong, P., Cinats, J., Courtenay, B., Feibel, R., Geulette, B., Gravel, C., Haas, N., Raschke, M., Hammacher, E., van der Velde, D., Hardy, P., Holt, M., Josten, C., Ketterl, R.L., Lindeque, B., Lob, G., Mathevon, H., McCoy, G., Marsh, D., Miller, R., Munting, E., Oevre, S., Nordsletten, L., Patel, A., Pohl, A., Rennie, W., Reynders, P., Rommens, P.M., Rondia, J., Rossouw, W.C., Daneel, P.J., Ruff, S., Rüter, A., Santavirta, S., Schildhauer, T.A., Gekle, C., Schnettler, R., Segal, D., Seiler, H., Snowdowne, R.B., Stapert, J., Taglang, G., Verdonk, R., Vogels, L., Weckbach, A., Wentzensen, A., and Wisniewski, T. 2002. Recombinant human bone morphogenetic protein-2 for treatment of open tibial fractures: a prospective, controlled, randomized study of four hundred and fifty patients. J. Bone Joint Surg. Am. 84-A: 2123-2134.

10. Gröngröft, I., Heil, P., Matthys, R., Lezuo, P., Tami, A., Perren, S., Montavon, P., and Ito, K. 2009. Fixation compliance in a mouse osteotomy model induces two different processes of bone healing but does not lead to delayed union. J. Biomech. 42: 2089-2096.

11. Jiang, X., Kalajzic, Z., Maye, P., Braut, A., Bellizzi, J., Mina, M., and Rowe, D.W. 2005. Histological analysis of GFP expression in murine bone. J. Histochem. Cytochem. 53: 593-602.

12. Kato, T., Kawaguchi, H., Hanada, K., Aoyama, I., Hiyama, Y., Nakamura, T., Kuzutani, K., Tamura, M., Kurokawa, T., and Nakamura, K. 1998. Single local injection of recombinant fibroblast growth factor-2 stimulates healing of segmental bone defects in rabbits. J. Orthop. Res. 16: 654-659.

13. Kawamoto, T. and Shimizu, M. 2000. A method for preparing 2- to 50-micron-thick fresh-frozen sections of large samples and undecalcified hard tissues. Histochem. Cell Biol. 113: 331-339.

14. Matsumoto, T., Mifune, Y., Kawamoto, A., Kuroda, R., Shoji, T., Iwasaki, H., Suzuki, T., Oyamada, A., Horii, M., Yokoyama, A., Nishimura, H., Lee, S.Y., Miwa, M., Doita, M., Kurosaka, M., and Asahara, T. 2008. Fracture induced mobilization and incorporation of bone marrow-derived endothelial progenitor cells for bone healing. J. Cell Physiol. 215: 234-242.

15. Matthys, R. and Perren, S.M. 2009. Internal fixator for use in the mouse. Injury 40: S103-109.

16. Molster, A., Gjerdet, N.R., Raugstad, T.S., Hvidsten, K., Alho, A., and Bang, G. 1982. Effect of instability of experimental fracture healing. Acta Orthop. Scand. 53: 521-526. 
17. Nakamura, T., Hara, Y., Tagawa, M., Tamura, M., Yuge, T., Fukuda, H., and Nigi, H. 1998. Recombinant human basic fibroblast growth factor accelerates fracture healing by enhancing callus remodeling in experimental dog tibial fracture. J. Bone Miner. Res. 13: 942-949.

18. Okazaki, H., Kurokawa, T., Nakamura, K., Matsushita, T., Mamada, K., and Kawaguchi, H. 1999. Stimulation of bone formation by recombinant fibroblast growth factor- 2 in callotasis bone lengthening of rabbits. Calcif. Tissue Int. 64: 542-546.

19. Otto, T.E., Patka, P., and Haarman, H.J. 1995. Closed fracture healing: a rat model. Eur. Surg. Res. 27: 277-284.

20. Rifkin, D.B. and Moscatelli, D. 1989. Recent developments in the cell biology of basic fibroblast growth factor. J. Cell Biol. 109: 1-6.

21. Seeherman, H., Li, R., and Wozney, J. 2003. A review of preclinical program development for evaluating injectable carriers for osteogenic factors. J. Bone Joint Surg. Am. 85A: $96-108$.

22. Taguchi, K., Ogawa, R., Migita, M., Hanawa, H., Ito, H., and Orimo, H. 2005. The role of bone marrow-derived cells in bone fracture repair in a green fluorescent protein chimeric mouse model. Biochem. Biophys. Res. Commun. 331: 31-
36.

23. Takada, K., Inaba, M., Ichioka, N., Ueda, Y., Taira, M., Baba, S., Mizokami, T., Wang, X., Hisha, H., Iida, H., and Ikehara, S. 2006. Treatment of senile osteoporosis in SAMP6 mice by intra-bone marrow injection of allogeneic bone marrow cells. Stem Cells 24 : 399-405.

24. Ueno, M., Urabe, K., Naruse, K., Uchida, K., Minehara, H., Yamamoto, T., Steck, R., Gregory, L., Wullschleger, M.E., Schuetz, M.A., and Itoman, M. 2011. Influence of internal fixator stiffness on murine fracture healing: two types of fracture healing lead to two distinct cellular events and fgf-2 expressions. Exp. Anim. 60: 79-87.

25. Wang, G.J., Dunstan, J.C., Reger, S.I., Hubbard, S., Dillich, J., and Stamp, W.G. 1981. Experimental femoral fracture immobilized by rigid and flexible rods (a rabbit model). Clin. Orthop. Relat. Res. 154: 286-290.

26. Zhang, Y., Adachi, Y., Suzuki, Y., Minamino, K., Iwasaki, M., Hisha, H., Song, C.Y., Kusafuka, K., Nakano, K., Koike, Y., Wang, J., Koh, E., Cui, Y., Li, C., and Ikehara, S. 2004. Simultaneous injection of bone marrow cells and stromal cells into bone marrow accelerates hematopoiesis in vivo. Stem Cells 22: 1256-1262. 